\title{
Neurodevelopmental Co morbidities of Poorly-Controlled Childhood Epilepsy: A Case-Control Study
}

\author{
Mohammad Asaduzzaman ${ }^{* 1}$, Md Mizanur Rahman², Mohammad Nadim Hasan ${ }^{3}$
}

\begin{abstract}
Introduction: The epilepsy associated co morbidities are often underestimated, consequently, undertreated. The aim of the present study was to determine neurodevelopmental co morbidities associated with poorly controlled childhood epilepsy. Materials and Methods: This retrospective study was performed from January 2007 to December 2008 at Paediatric Neurology outpatient department in Bangabandhu Sheikh Mujib Medical University, Dhaka, among the children with epilepsy of 7 months to 15 years age who had history of at least 6 months treatment with rational antiepileptic drugs daily with adequate compliance. There were two groups of patients; group 1, consisted of 50 poorly controlled epilepsy patients and group 2, comprised 50 well-controlled epilepsy patients. We retrospectively reviewed EEGs and medical records from these children. Features of neurolodevelopmental co morbidities were compared between the two groups. Results: In this study, initial EEG was abnormal significantly in poorly controlled group $(O R=5.27$; $p=0.025)$. Co morbidities- cerebral palsy, language and speech delay, motor delay, microcephaly and cognitive disability were significantly higher in poorly-controlled epilepsy group compared to well-controlled epilepsy group (60.0\% vs. $24.0 \%, p<0.001 ; 74.0 \%$ vs. $38 \%, p<0.001 ; 72 \%$ vs. $40 \%, p<0.01 ; 60 \%$ vs. $30.0 \%, p<0.01$; $70 \%$ vs 32\%, $p<0.001$ respectively). Conclusion: The study showed several neurodevelopment co morbidities that can be identified early in the course of childhood epilepsy which can predict development of poor seizure control. Knowledge of these co morbidities will help us to discriminate our patient and can inform therapeutic choices.
\end{abstract}

Keywords: Neurodevelopment, Co morbidities, Poorly-controlled epilepsy.

Number of Tables: 04; Number of References: 33; Number of Correspondence: 03.

*1. Corresponding Author:

Dr. Mohammad Asaduzzaman

MD (Paediatrics)

Assistant Professor (Paediatrics)

Sheikh Hasina Medical College, Jamalpur.

Email: drmdzaman1973@gmail.com

Mobile number: 01712000511

2. Professor Md. Mizanur Rahman

Ex Professor \& Chairman

Department of Paediatric Neurology

BSMMU, Dhaka, Bangladesh.

3. Dr. Mohammad Nadim Hasan

FCPS (Medicine)

Assistant Professor

Department of Medicine

Sheikh Hasina Medical College, Jamalpur.

\section{Introduction:}

Epilepsy is still an issue that perplexes the epileptologists worldwide, with a reported impact on 50 million populations ${ }^{1}$. Seizures affect $4-7 \%$ of children ${ }^{2}$. Epilepsy is considered to be present when two or more unprovoked seizures occur at an interval greater than 24 hours apart $^{3}$. One or more seizures per month over a period of 6 months or more even after experiencing trials of at least two different antiepileptic drugs alone or in combination at optimum doses with adequate compliance is called intractable epilepsy ${ }^{4}$. Epilepsy is refractory when seizures are so frequent or severe that they limit the patient's ability to live life fully according to his or her wishes or necessitate the use of medications that, although effective, produce adverse effects ${ }^{5}$. Neurodevelopmental function is a basic brain process that may be needed for learning and productivity ${ }^{3}$.

The term "co morbidity" refers to one or more other disease among people with an index disease ${ }^{6}$. With the reconceptualization of epilepsy as a disease of brain network, it is great timing to rethink epilepsy and those associated comorbidities, including cognitive and behavioral co morbidities, psychiatric co morbidities, cardiovascular disease and migraines ${ }^{1}$. The epilepsy associated co morbidities are often underestimated, consequently, undertreated. Furthermore, cognitive deficits always remain despite seizure greatly control ${ }^{7}$. Cognitive and behavioural co morbidities are often seen in children with epilepsy, and are more common and severe in refractory epilepsy. These comorbidities are associated with worse quality of life, increased behavioural and language problems and worse social skills, all of which adversely affect long-term psychosocial functioning. The location of the epileptic focus can, to a certain degree, predict the type(s) of comorbidity ${ }^{8}$.

Epilepsy may disrupt brain functions necessary for language development by its associated intellectual disabilities or directly as a consequence of the seizure disorder. Any process that impairs language function has long-term consequences for academic, social, and occupational adjustments in children and adolescents with epilepsy. Furthermore, impairments in specific language abilities 
can impact memory and learning abilities 9 . Epilepsy appear in more than $20 \%$ of children with cerebral palsy, unspecified cognitive impairment, pervasive developmental delay, as well as in specific genetic syndromes associated with cognitive impairment. In addition, there are different types of epilepsy that may be associated with different types of developmental disability. Both the paper electroencephalogram (EEG) and the video EEG remain the most valuable tools that are used to evaluate patients with both epilepsy and a developmental disorder ${ }^{10}$. There are different studies regarding the co-morbidity of epilepsy and numerous childhood onset conditions, like cerebral palsy, autism, down syndrome, and mental retardation ${ }^{11,12,13}$. A recent study in pediatric population with cerebral palsy indicates that $35 \%$ have a history of epilepsy ${ }^{14}$. Among individuals with severe/profound mental retardation, increased rates of underlying neurological abnormalities are manifested by a higher frequency of mixed seizure disorders and an onset of seizures in infancy or early childhood. This factor contributes to higher rates of uncontrollable seizures and neuropsychiatric complications. One Bangladeshi study showed that the neuropsychiatric, developmental and pain disorders are quite common co morbid conditions among epilepsy patients ${ }^{15}$.

As literatures were reviewed there were few published data about this type of study in our country. But there is no study in our country related to co morbidities and poor seizure control. There are a number of conditions to be co morbid with epilepsy, the improved knowledge base of which is very much important. The awareness of co morbidities can improve diagnosis. Some co morbidities may influence the prognosis of epilepsy. The recognition of co morbidities can inform therapeutic choices. This study is aimed to find out the different neurodevelopmental co morbid conditions in poorly-controlled childhood epilepsy patients.

\section{Materials and Methods:}

This case-control study was conducted from January 2007 to December 2008 at Paediatric Neurology OPD, Bangabandhu Sheikh Mujib Medical University. 50 cases of poorly-controlled epilepsy in group-1 and 50 cases of well-controlled epilepsy in group-2 were enrolled in the study. Children of either sex with epilepsy aged 7 months to 15 years with history of at least one unprovoked seizure per month for 6 or more months and history of treatment with 2 or more rational antiepileptic drugs (AED) daily, either singly or in combination for at least 6 months and adequate compliance to antiepileptic drugs were considered as case. Children of either sex with epilepsy, aged 7 months to 15 years who had been seizure-free during 6 months after start of treatment were considered as control. Poorly controlled epilepsy was defined as one or more seizure per month over a period of 6 months or more even after experiencing trials of at least two different antiepileptic drugs alone or in combination at optimum doses with adequate compliance. Well-controlled epilepsy was defined as no seizure during 6 months after start of treatment with AED.

Once the child was reporting, a structured questionnaire was completed, containing pre-defined variables of neurodevelopmental co morbidities that may help predicting the poor seizure control. Then a detailed history including gender, age of onset, initial EEG status, cerebral palsy, language and speech delay, motor delay, cognitive disability and Microcephaly etc. were recorded and medical records were reviewed. Details regarding antiepileptic drugs were recorded i.e. number of drugs, duration of therapy, dosage and compliance. It was noted whether the choice of drugs were correct or incorrect in relation to seizure type and the dosage schedule was proper according to body weight. Thorough physical examination including neurodevelopmental and psychological assessment was done. Cognitive status was determined by results of tests of global cognitive functioning. Clinical syndromes like Autism, Attention-Deficit Hyperactivity Disorder (ADHD), Down syndrome were included under variable, cognitive disability. All study patients were seen by a consultant Paediatric Neurologist of the unit. Seizures were classified using the International League Against Epilepsy (ILAE) classification of epileptic seizure. First Interictal EEG recordings obtained with a 19 channel Electroencephalograph, employing scalp electrodes placed according to the international 10-20 system were studied. Serum drug level was not measured. An antiepileptic drug was considered to have failed if it did not control seizures in spite of good compliance or if medication was discontinued because of unacceptable side effects. A drug used acutely to treat status epilepticus was not counted as one of the two AEDs. Child was a case or a control. Group1 consisted of poorly controlled epilepsy patients and Group 2 comprised well-controlled epilepsy patients. A comparison of various neurodevelopmental co morbidities between the two groups was done. Data were analyzed using statistical package SPSS (version 15.0). Standard tests of significance, such as Chi-square test was applied for categorical variables and ' $\mathrm{t}$ ' test was done for quantitative variables. 95\% confidence interval $(\mathrm{CI})$ and $\mathrm{p}$ values were also computed. P-value of $<0.05$ was considered significant. Binary logistic regression analysis was performed to determine independently significant variables.

\section{Results:}

Table I shows that $54 \%$ of the poorly-controlled epilepsy patients and $44 \%$ of well controlled epilepsy patients were between 1-5 years age group. However there was wide spread distribution in different age groups. The mean age was found to be $4.59 \pm 3.19$ years in poorly-controlled group and $5.91 \pm 3.72$ years in well- controlled group. No significant statistical difference was observed between poorly-controlled and well-controlled group in respect to age $(p=0.062)$. In poorly-controlled group $60.0 \%$ were males and $40.0 \%$ were females, while in well-controlled 
group males and females were $66.0 \%$ and $34.0 \%$ respectively. There was no significant statistical difference between the two groups in respect to $\operatorname{sex}(\mathrm{p}=0.534)$.

Table-I: Distribution of the subjects by demographic variables $(n=100)$.

\begin{tabular}{clll}
\hline \multirow{2}{*}{ Variables } & \multicolumn{2}{c}{ Groups } & p value \\
\cline { 2 - 3 } & $\begin{array}{c}\text { Group1 (n=50) } \\
\text { No (\%) }\end{array}$ & $\begin{array}{c}\text { Group2 (n=50) } \\
\text { No (\%) }\end{array}$ & \\
\hline Age (year) & & $1(2.0)$ & \\
$\quad$ o $\leq 1$ year & $5(10.0)$ & $22(44.0)$ & \\
o 1-5 years & $27(54.0)$ & $20(40.0)$ & \\
o 5-10 years & $16(32.0)$ & $7(14.0)$ & \\
o $>10$ years & $2(4.0)$ & $5.91 \pm 3.72$ & $0.062^{\mathrm{NS}(\mathrm{a})}$ \\
Mean \pm SD & $4.59 \pm 3.19$ & & \\
Sex & & $17(34.0)$ & \\
$\quad$ o Female & $20(40.0)$ & $33(66.0)$ & $0.534^{\mathrm{NS}(\mathrm{b})}$ \\
o Male & $30(60.0)$ & & \\
\hline
\end{tabular}

${ }^{\mathrm{a}}$ Unpaired $\mathrm{t}$ test was done to measure the level of significance. ${ }^{\mathrm{b}} \mathrm{Chi}$-square test was done to measure the level of significance. NS= not significant

Table II shows that $96.0 \%$ of the patients in poorly-controlled epilepsy group had abnormal EEG in contrast to $82.0 \%$ of the patients in well-controlled epilepsy group $(\mathrm{p}<0.05)$.

Table II: Distribution of the subjects by initial EEG status $(n=100)$.

\begin{tabular}{lllll}
\hline \multirow{2}{*}{ EEG } & \multicolumn{2}{c}{ Groups } & \multirow{2}{*}{ OR (CI) } & p value \\
\cline { 2 - 3 } & $\begin{array}{l}\text { Group1 }(\mathrm{n}=50) \\
\text { No }(\%)\end{array}$ & $\begin{array}{l}\text { Group2 }(\mathrm{n}=50) \\
\text { No }(\%)\end{array}$ & & \\
\hline Normal & $2(4.0)$ & $9(18.0)$ & \multicolumn{2}{c}{$0.025^{*}$} \\
Abnormal & $48(96.0)$ & $41(82.0)$ & $5.27(1.08-25.78)$ \\
\hline
\end{tabular}

Chi-square test was done to measure the level of significance. ${ }^{*} \mathrm{p}<0.05$ Group1: Poorly- controlled epilepsy

Group2: well-controlled epilepsy

$\mathbf{n}=$ number of patients

Table III demonstrates that associated cerebral palsy, language and speech delay, motor delay, Microcephaly and cognitive disabilities were significantly higher in poorly-controlled epilepsy group compared to well-controlled epilepsy group $(60.0 \%$ vs. $24.0 \%$, p $<0.001 ; 74.0 \%$ vs. $38 \%$, p $<0.001 ; 72 \%$ vs. $40 \%$, p $<0.01 ; 60 \%$ vs. $30.0 \%, \mathrm{p}<0.05 ; 70 \%$ vs. $32 \%, \mathrm{p}<0.001$ respectively.

Table III: Distribution of the subjects by neurodevelopmental co morbidities $(\mathrm{n}=100)$.

\begin{tabular}{lccc}
\hline \multirow{2}{*}{ Variables } & \multicolumn{2}{c}{ Groups } & \multirow{2}{*}{ p value } \\
\cline { 2 - 3 } & $\begin{array}{c}\text { Group1 (n=50) } \\
\text { No (\%) }\end{array}$ & $\begin{array}{c}\text { Group2 (n=50) } \\
\text { No (\%) }\end{array}$ & \\
\hline Cerebral palsy (CP) & $30(60.0)$ & $12(24.0)$ & $<0.001^{*}$ \\
Motor delay & $36(72.0)$ & $20(40.0)$ & $<0.01^{*}$ \\
Language \& speech delay & $37(74.0)$ & $19(38.0)$ & $<0.001^{*}$ \\
Microcephaly & $30(60.0)$ & $15(30.0)$ & $<0.05^{*}$ \\
Cognitive disability & $35(70.0)$ & $16(32.0)$ & $<0.001^{*}$ \\
\hline
\end{tabular}

Chi-square test was done to measure the level of significance. ${ }^{*}$ p $<0.05$ Group1: Poorly- controlled epilepsy Group2: well-controlled epilepsy

$\mathbf{n}=$ number of patients
Table IV shows Binary logistic regression performed to assess the impact of several factors on poor seizure control. The model contained five independent predictors (cerebral palsy, motor delay, language and speech delay, Microcephaly and cognitive disability). Only two of the independent variables (language and speech delay and cognitive disability) made a unique statistically significant contribution to the model ( $\mathrm{P}=0.020$ and $\mathrm{p}=0.014$ respectively).

Table IV: Binary Logistic Regression Results for Detection of co morbidity.

\begin{tabular}{lccc}
\hline Variables & Significance & $\begin{array}{c}\text { Odds Ratio } \\
\text { (OR) }\end{array}$ & $\begin{array}{c}\text { 95\% CI for } \\
\text { OR }\end{array}$ \\
\hline Cerebral palsy & 0.135 & 0.433 & $0.145-1.298$ \\
Motor delay & 0.270 & 0.525 & $0.168-1.647$ \\
Language and speech delay & $0.020^{*}$ & 0.306 & $0.112-0.832$ \\
Microcephaly & 0.680 & 1.285 & $0.390-4.239$ \\
Cognitive disability & $0.014^{*}$ & 0.305 & $0.118-0.789$ \\
\hline
\end{tabular}

*Statistically significant $(\mathrm{P}<0.05) \quad \mathrm{CI}=$ Confidence Interval

\section{Discussion:}

This study was done to search the neurodevelopmental co morbidities that are associated with the poor control of childhood epilepsy. This retrospective study demonstrated that there were a number of co morbid conditions that were associated with poor seizure control. Early identification of these factors might help in planning early intervention.

Table I illustrates the demographic characteristics of the patients. Age (mean \pm SD) at presentation of poorly controlled group was $4.59 \pm 3.19$ years and that of well-controlled group was $5.91 \pm 3.72$ years. No significant statistical difference was observed between poorly controlled and well-controlled group in respect to age $(p=0.534)$. In poorly controlled group males were $(60.0 \%)$ and females were $(40.0 \%)$ and in well-controlled group males and females were $66.0 \%$ and $34.0 \%$ respectively. In both groups males were predominant. No significant statistical difference was observed in this study in respect to sex between poorly controlled and well-controlled group $(p=0.062)$ that is poor seizure control occurs with equal frequency in both sexes. This finding was supported by the study done by Kwan P et al. ${ }^{16}$ who did not find any significant difference in sex between the groups that become seizure free and the group with uncontrolled seizure. They found that $52 \%$ of the patients with uncontrolled epilepsy were male and $47 \%$ were female, whereas $47 \%$ male and $53 \%$ female were found in patients who were seizure free. But Malik et al. ${ }^{17}$ found that male gender was a risk factor for intractable seizures $(p=0.001)$ and this finding was similar to that previously done by Akhondian et al. ${ }^{18}$ The male predominance in this study was more likely to be because of a selection bias.

Table II shows that $96.0 \%$ of the patients in poorly controlled group have abnormal EEG in contrast to $82.0 \%$ 
of patients in well-controlled group. EEG abnormality was significantly associated with poor seizure control $(p=$ 0.025). This finding was similar to those done by many authors. Singhi et $\mathrm{al}^{19}$ found that EEG was abnormal more in intractable epilepsy patients $(69 \%$ cases $)$. Banu et al. ${ }^{20}$ found that EEG was abnormal in $80.8 \%$ cases and it was found to be associated with more than 4 times $(\mathrm{OR}=4.09)$ risk to poor seizure remission $(p=0.0016)$. Similar finding was seen by Akhondian et al. ${ }^{18}$ who found that the first EEG was abnormal in $96.1 \%$ of patients in the intractable group and in $83.8 \%$ of the patients in the well-controlled group $(\mathrm{p}=0.031)$. Another study carried out by Malik et al. ${ }^{17}$ found that higher proportion of the patients with abnormal EEG continued to have seizures during the study period compared to patients with normal EEG (63\% vs. $19 \% ; \mathrm{OR}=7.28 ; 95 \% \mathrm{CI}=4.34-12.18 ; \mathrm{p}$-value $<0.001$.

Table III demonstrates that cerebral palsy, language and speech delay, motor delay and microcephaly and cognitive disability were present more in poorly-controlled epilepsy compared to well-controlled epilepsy $(60.0 \%$ vs. $24.0 \%$; $74.0 \%$ vs. $38 \%$; $72 \%$ vs. $40 \%$; $60 \%$ vs. $30.0 \%$ and $70 \%$ vs. $32 \%$ respectively).

Cognitive disability previously called 'Mental Retardation' was found as a predictor of poor seizure remission ( $p$ $<0.001$ )as shown in table III. This finding was relevant to that done by Ko and Holmes ${ }^{21}$. They showed that $20.1 \%$ patients in intractable group compared to $2.6 \%$ in controlled group had mental retardation $(\mathrm{p}=0.03)$. Singhi et al. ${ }^{19}$ found that mental retardation was present in $11.0 \%$ of intractable epilepsy patients and it was found to be a poor prognostic factor. Oskoui et al. ${ }^{22}$ showed that mental retardation at onset was a significant risk for intractability $(\mathrm{OR}=7.2)$. Huttenlocher \& Hapke ${ }^{23}$ found that the majority of children with uncontrollable seizures (61\%) were mentally retarded and remission of seizures was much less frequent ( $1.5 \%$ / year) in this group with mental retardation. One Bangladeshi study Chowdhury RN et al ${ }^{15}$ showed that Mental retardation was more common and significantly associated $(p=0.0001)$ with generalized epilepsy patients.

This study shows that $60 \%$ of the patients in poorly controlled group have Microcephaly compared to 30\% of the patients in well controlled group. Microcephaly is significantly associated with poor seizure control $(p<0.05)$. This finding is relevant to those done by many authors. Chawla et al. ${ }^{24}$ found microcephaly in $58 \%$ cases of intractable epilepsy compared to only $1 \%$ cases of well-controlled epilepsy. But Berg et al. ${ }^{25}$ found $23.7 \%$ microcephaly in cases compared to $3.1 \%$ in controls. Yilmaz et $\mathrm{al}^{26}$ showed that Strong univariate association was observed between intractability and Microcephaly. Microcephaly is present in $29 \%$ in intractable epilepsy compared to $10.1 \%$ in drug responsive group $(\mathrm{p}<0.001)$.

Motor delay was present in $72 \%$ of the cases in poorly controlled epilepsy as compared to $40 \%$ of the patients in well controlled group ( $p<0.01$ ). Ko and Holmes ${ }^{21}$ also found motor delay in 34\% of intractable group compared to 7.7 of controlled group $(\mathrm{p}<0.01)$. Yilmaz et $\mathrm{al}^{26}$ showed that Strong univariate association was observed between intractability and motor developmental delay. They found that motor delay is present in $82 \%$ in intractable epilepsy compared to $28.8 \%$ in drug responsive group ( $p<0.001$ ). Oskui et $\mathrm{al}^{27}$ found that this factor is predictive of poor seizure outcome (odds ratio 8.9).

Table III also shows that $60.0 \%$ of the patients in poorly controlled group have cerebral palsy in contrast to $24.0 \%$ of patients in well-controlled group $(p<0.001)$. This finding was similar to those done by many authors. Chowdhury et $\mathrm{al}^{15}$ found that cerebral palsy was more common and significantly associated $(\mathrm{p}=0.005)$ with generalized epilepsy patients. A study about children with cerebral palsy by Singhi et $\mathrm{al}^{14}$ indicate that seizure control in children with cerebral palsy is difficult and could be achieved in just over half of the patients. Among the 105 children with CP \& seizure, 45 (58.1\%) children got seizure control, most of them requiring poly-therapy. Cerebral palsy is present in $13.9 \%$ of children with epilepsy as compared to $0.3 \%$ in general child population (odds ratio $=55.9 \%$ ) as shown by Aaberg et $\mathrm{al}^{28}$. It has been recognized that children with cerebral palsy have low seizure remission rates of about $12.9 \%$ to $14 \%$ and high relapse rates of $41.5 \%$ to $62.5 \%$ showed by Aksu et $\mathrm{al}^{29}$ \& Delgado et $\mathrm{al}^{30}$.

The present study showed that language and speech delay was present in $74 \%$ cases of poorly controlled epilepsy in comparison to $38 \%$ of the cases in well-controlled group $(p$ $<0.001$ ). Several studies (Fastenau et $\mathrm{al}^{31} \&$ Caplan et $\mathrm{al}^{32}$ ) found that children with absence epilepsy had worse language performance than children with focal epilepsy. In contrast, Hermann et $\mathrm{a}^{13}$ found that children with focal but not generalized epilepsy had poorer language than controls. Ko and Holmes ${ }^{21}$ found that $20.1 \%$ cases in intractable group had language delay compared to $7.7 \%$ in controlled group. But did not found any statistical difference between two groups $(p=0.08)$. It is not only acute seizures or epileptiform discharges that cause language dysfunction, but that chronic changes to underlying networks may cause persistent language problems.

Independent co morbidities associated with poor seizure control after binary logistic regressions were language and speech delay and cognitive disability.

\section{Conclusion:}

The study showed several neurodevelopmental co morbidities that can be identified early in the course of childhood epilepsy which can predict development of poor seizure control. Knowledge of these comorbidities will help us to discriminate our patient and can inform therapeutic choices.

\section{Conflict of Interest: None.}

\section{Acknowledgement:}

Thanks and all praise to Almighty Allah, the beneficent, the merciful for providing us enough energy and patience to 
complete this article. Our special thanks and gratitude to Prof (Dr) C.A. Kawser, Professor and Ex chairman, Department of General Paediatrics, Bangabandhu Sheikh Mujib Medical University, Dhaka, Bangladesh for providing instructions, encouragement and valuable advice from beginning of this study. We would like to express our sincere gratitude and gratefulness to all teachers, doctors and employee in the department of paediatrics, Bangabandhu Sheikh Mujib Medical University, Dhaka, Bangladesh for valuable suggestions and advices to complete this study.

\section{References:}

1. Wang X, He X, Luan G. Comorbidities of Refractory Epilepsy and the Update Mechanism. Neuropsychiatry. 2017; S(1):45-48.

2. Kalra V. Practical paediatric neurology. 2nd ed. New Delhi: Arya Publications; 2008

3. Johnston MV. Seizures in childhood. In: Behrman RE, Kleigman RM and Jenson HB, editors. Nelson Text book of Paediatrics. 17th ed. Philadelphia: Saunders; 2004: 1993-2009.

4. Chawla S, Aneja S, Kashyap R, Mallika V. Etiology and clinical predictors of intractable epilepsy. Pediatr Neurol. 2002; 27( 3): 186-191.

https://doi.org/10.1016/S0887-8994(02)00416-2

5. Devinsky O. Patients with refractory seizures. The New England journal of Medicine.1999; 340(20): 1565-1570.

https://doi.org/10.1056/NEJM199905203402008

PMid: 10332020

6. Feinstein AR. The pre-therapeutic classification of co-morbidity in chronic disease. J Chron Dis. 1970; 23:455-69.

7. Reilly C, Atkinson P, Das KB. Neurobehavioral comorbidities in children with active epilepsy: a population-based study. Pediatrics. 2014; 133(6): e1586-93.

8. Nickels KC, Zaccariello MJ, Hamiwka LD, Wirrell EC. Cognitive and neurodevelopmental comorbidities in paediatric epilepsy. Nat Rev Neurol. 2016;12(8):465-76.

PMID: 27448186 DOI: 10.1038/nrneurol. 2016.98

9. Wheless JW, SimosIan PG, Butler IJ. Language dysfunction in epileptic conditions. Seminars in Pediatric Neurology.2002;9(3):218-228.

10. Persad V, Thompson MD, Percy ME. Epilepsy and developmental disability. Journal on Developmental Disabilities. 10 (2): 123-152.

11. Brodtkrob, E. The diversity of epilepsy in adults with severe developmental disabilities: Age at seizure onset and other prognostic factors. Seizure. 1994; 3: 277-285.

12. Johannsen, P., \& Christensen, J. Epilepsy in Down syndrome Prevalence in three groups. Seizure. 1996; 5: 121-125.

13. Volkmar, F., \& Nelson, D. S. Seizure disorders in autism. Journal of the American Academy of Child and Adolescent Psychiatry.1990; 29: 127- 129.
14. Singhi, P., Jagirdar, S., Khandelwal, N., et al. Epilepsy in children with cerebral palsy. Journal of Child Neurology. 2003; 18: 174-179.

15. Chowdhury RN, 1 Hasan AH, Rahman KM, Deb SR. Co-Morbidities among Epilepsy Patients: Experience In Bangladesh. Bangladesh J Medicine. 2013; 24 : 65-69.

16. Kwan P, Brodie MJ. Early identification of refractory epilepsy. N Eng J Med. 2000; 342: 314 - 319.

https://doi.org/10.1056/NEJM200002033420503

PMid:10660394 .

17. Malik MA, Hamid MH, Ahmed TM, Ali Q. Predictors of intractable childhood epilepsy. Journal of the College of Physicians and Surgeons Pakistan. 2008;18(3):158-162.

18. Akhondian J, Heydarian F, Jafari, SA. Predictive factors of pediatric intractable seizure. Arch Iranian Med. 2006; 9(3): 236-239.

19. Singhvi JP, Sawhney IM, Lal V, Pathak A, Prabhakar, S. Profile of intractable epilepsy in a tertiary referral centre. Neurol India. 2000; 48(4): 351-356.

20. Banu SH, Khan NZ, Jahan A, Parveen M, Rahman N, Boyd SH, et al. Profile of childhood epilepsy in Bangladesh. Developmental Medicine and Child Neurology. 2003; 45: 477-482.

https://doi.org/10.1017/S0012162203000884

https://doi.org/10.1111/j.1469-8749.2003.tb00943.x

PMid:12828402.

21. Ko TS, Holmes GL. EEG and clinical predictors of medically intractable childhood epilepsy. Clinical Neurophysiology.1999; 110: 1245-1251.

https://doi.org/10.1016/S1388-2457(99)00068-1

22. Oskoui M, Webster RI, Zhan X, Shevell, MI. Factors predictive of outcome in childhood epilepsy. Child Neurol. 2005;20(11): 898-904.

23. Huttenlocher PR, Hapke RJ. A follow up study of intractable seizures in childhood. Annals of Neurology. 1990; 28(5):699-705.

DOI: 10.1002/ana.410280516 PMID: 2260857

24. Chawla S, Aneja S, Kashyap R, Mallika V. Etiology and clinical predictors of intractable epilepsy. Pediatr Neurol. 2002; 27( 3): 186-191.

https://doi.org/10.1016/S0887-8994(02)00416-2

25. Berg AT, Levy SR, Novonty EJ, Shinnar S. Predictors of intractable epilepsy in childhood: a case-control study. Epilepsia.1996;37(1):24-30.

26. Yilmaz BS, Okuyaz C, Komur M. Predictors of Intractable Childhood Epilepsy. Pediatric Neurol. 2013; 48(1): 52-55.

https://doi.org/10.1016/j.pediatrneurol.2012.09.008

27. Oskoui M, Webster RI, Zhan X, Shevell, MI. Factors 
predictive of outcome in childhood epilepsy. Child Neurol. 2005;20(11): 898-904.

28. Aaberg KM, Bakken IJ, Lossius MI, Soraas CL, Haberg SE, Stolenberg C, et al. Comorbidity and Childhood Epolepsy: A Nationwide Registry Study. Pediatrics. 2016; 138 (3): e2016092

DOI: https://doi.org/10.1542/peds.2016-0921 .

29. Aksu F. Nature and prognosis of seizures in patients with cerebral palsy. Dev Med Child Neurol. 1990;32:661-668.

30. Delgado MR, Reila AR, Mills J. Discontinuation of antiepileptic drug treatment in children with cerebral palsy. Pediatrics. 1996; 97:192-197.
31. Fastenau PS, Johnson CS, Perkins SM, Byars AW, deGrauw TJ, Austin JK, et al. Neuropsychological status at seizure onset in children: risk factors for early cognitive deficits.Neurology. 2009; 73:526-34. [PubMed: 19675309] 32. Caplan R, Siddarth P, Vona P, Stahl L, Bailey C, Gurbani S, et al. Language in pediatric epilepsy. Epilepsia. 2009; 50:2397-407. [PubMed: 19624713]

33. Hermann B, Jones J, Sheth R, Dow C, Koehn M, Seidenberg M. Children with new-onset epilepsy: neuropsychological status and brain structure. Brain. 2006; 129:2609-19. [PubMed: 16928696] 